\title{
Measurement and Identification Source Characteristic of VOCs in Map Ta Phut Industrial Estate of Thailand using Multivariate Analysis Technique
}

\author{
${ }^{1,3}$ Jatupat Mekparyup and ${ }^{2,3 *}$ Kidakan Saithanu \\ ${ }^{1,2}$ Department of Mathematics, Faculty of Science, Burapha University 169 Muang, Chonburi, Thailand, \\ ${ }^{3}$ Centre of Excellence in Mathematics, Commission on Higher Education, Ratchathewi, Bangkok, Thailand.
}

Correspondence Author: Kidakan Saithanu, Department of Mathematics, Faculty of Science, Burapha University169 Muang, Chonburi, Thailand. E-mail:- ksaithan@buu.ac.th

Received date: 15 June 2019, Accepted date: 24 August 2019, Online date: 29 August 2019

Copyright: (C) 2019 Jatupat Mekparyup and Kidakan Saithanu, This is an open-access article distributed under the terms of the Creative Commons Attribution License, which permits unrestricted use, distribution, and reproduction in any medium, provided the original author and source are credited.

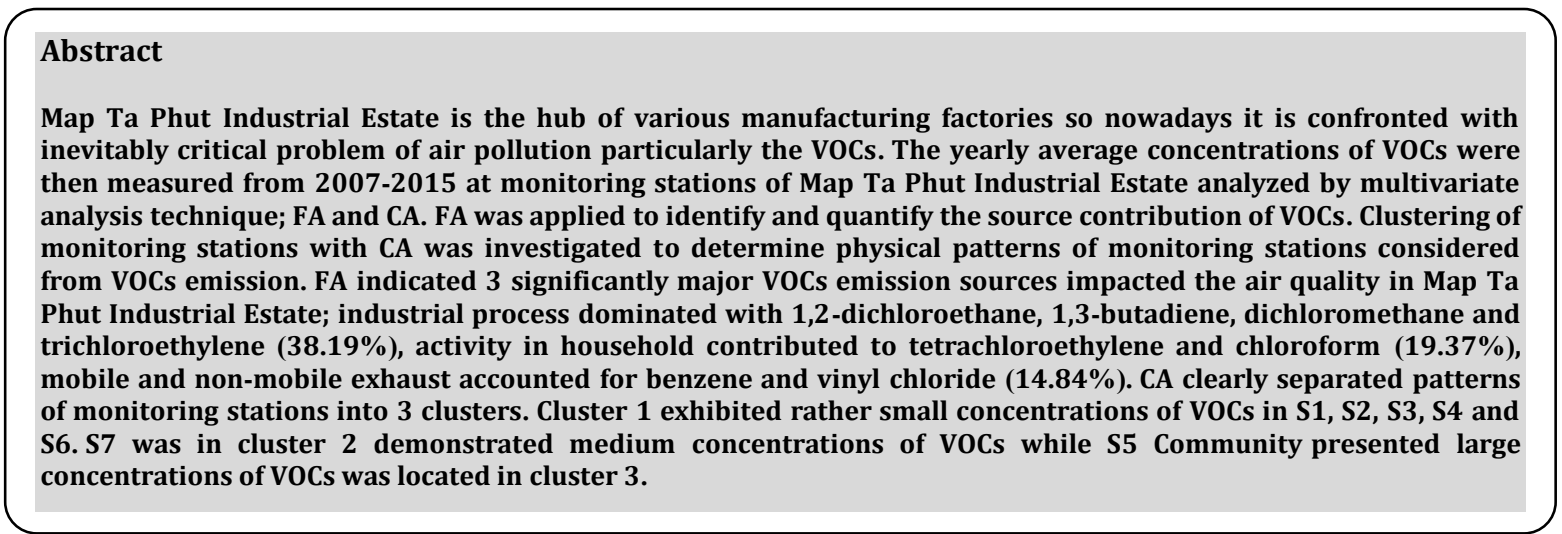

Keywords: VOCs, Map Ta Phut Industrial Estate, Multivariate analysis

\section{INTRODUCTION}

Volatile organic compounds or VOCs are organic chemicals that easily evaporate and diffuse at normal temperature and pressure. The composition of VOCs principally consists of carbon $(\mathrm{C})$ and hydrogen $(\mathrm{H})$ or maybe confounded with other elements such as oxygen $(\mathrm{O})$, fluoride $(\mathrm{F})$, chloride $(\mathrm{Cl})$, bromide $(\mathrm{Br})$, sulfur $(\mathrm{S})$ and nitrogen $(\mathrm{N})$. The VOCs are mainly separated into 2 groups; non-halogenated hydrocarbons and halogenated hydrocarbons. Some VOCs, like benzene, are toxic and carcinogenic which are regulated as perilous air pollutants. Nowadays, VOCs emissions are discharged in a large amount because they are widely used in various industrial processes and human activities. The VOCs are then become one of seriously important causes of air pollution problem which government of each country gives priority to resolve.

Map Ta Phut Industrial Estate is located in Map Ta Phut sub-district, Rayong province, east of Thailand. Map Ta Phut complex is comprising of 5 industrial estates so it is the largest one in Thailand also it is high productivity in manufacturing of petrochemicals, oil refineries, motor vehicles, agriculture and textile. Due to Map Ta Phut Industrial Estate furtherly expands more areas for increasing potency, it presently gets in trouble with seriously crucial air pollution. Furthermore, different VOCs are emitted by different sources such as industry, residential household or vehicles, etc. Identification source characteristic and major sources of VOCs as well their contributions to VOCs emission are crucial issues to develop an effective air pollution control strategy in Map Ta Phut Industrial Estate. Factor analysis (FA) with principal component extraction is multivariate method which is extensively applied to identify and quantify the various sources contributing to the VOCs levels; for example, GUO et al. (2004), MARCIANO et al. (2008), GENG et al. (2009), HUANG et al. (2012) and KHANTEE and THEPANONDH (2014).

This study therefore focused on source identification and apportionment of VOCs in Map Ta Phut Industrial Estate with principal component analysis (PCA) and factor analysis (FA). Cluster analysis (CA), one of multivariate techniques, was furthermore used to explore and explain physical patterns of monitoring stations in Map Ta Phut Industrial Estate. 
Citation: Jatupat Mekparyup and Kidakan Saithanu., Measurement and Identification Source Characteristic of VOCs in Map Ta Phut Industrial Estate of Thailand using Multivariate Analysis Technique. Australian Journal of Basic and Applied Sciences, 13(8): 64-68. DOI: 10.22587/ajbas.2019.13.8.10

\section{MATERIALS AND METHODS}

Air Quality and Noise Management Bureau, Pollution Control Department of Thailand furnished the yearly average 9 concentrations of VOCs since 2007 to 2015; Benzene, Vinyl Chloride, 1,2-Dichloroethane, Trichloroethylene, Dichloromethane, 1,2-Dichloropropane, Tetrachloroethylene, Chloroform and 1,3-Butadiene, at 7 monitoring stations of Map Ta Phut Industrial Estate of Thailand; Health Promotion Hospital Map Ta Phut (S1), Map Chalute Temple (S2), Wat Nong Fap School (S3), Muang Mai Map Ta Phut (S4), Ban Plong (S5), Ban Ta Kuan Public Health Center (S6) and Nop Pakate Village (S7). To identify and quantify the source contribution of VOCs in Map Ta Phut Industrial Estate, descriptive statistics and multivariate analysis technique were applied as following these steps.

1. Descriptive statistics with mean and standard error (SE.) was considered to study general characteristic of concentration for each of VOCs.

2. Factor analysis with principal component extraction and varimax rotation was utilized to discover the significant factors resulted in discharging VOCs emission.

Factor analysis technique employs eigenvalues to apportion data sets so it is often applied for source apportionment studies. It is a data reducing method for large data sets where correlated data is reduced to a small number of independent factors or principal components which can explain data variation. Rotational tools are usually used to obtain a better pattern of factor loadings without changing the relative locations of variables in space. Varimax, one of rotation methods, is universally used in climatic data manipulation to identify the principal components extracted with clear pattern of factor loadings (THURSTON and SPENGLER, 1985 and GUO et al., 2004). Generally, the orthogonal factor model with $m$ common factors is formulated as Equation 1 (JOHNSON and WICHERN, 2007).

$$
\underset{(p \times 1)}{\mathbf{X}}=\underset{(p \times 1)}{\boldsymbol{\mu}}+\underset{(p \times m)}{\mathbf{L}} \underset{(m \times 1)}{\mathbf{F}}+\underset{(p \times 1)}{\boldsymbol{\varepsilon}}
$$

where $^{\left(\mathbf{X}^{\mathbf{X}}\right)}$ is the observation vector of $p$ components, $\underset{(p \times 1)}{\boldsymbol{\mu}}$ is the mean vector of $p$ components, ${ }_{(p \times m)}^{\mathbf{L}}$ is the matrix of factor loadings of the $i$ th component; ${ }^{i=1,2, \ldots, p}$, on the $j$ th factor; $j=1,2, \ldots, m, \underset{(m \times 1)}{\mathbf{F}}$ is the $j$ th common factor and $(p \times 1)$ is $\mathrm{t}$ the $i$ th specific factor.

3. Cluster analysis with hierarchical technique and single linkage was performed to determine the physical pattern for each of monitoring stations.

Agglomerative hierarchical method of cluster analysis starts with the individual variables thus there are firstly as many as clusters as variables. The most similar variables are initially grouped and these initial first groups are combined according to their similarities. As the similarity decreases, all subgroups are blended into a single cluster. A two-dimensional diagram illustrated the result of agglomerative hierarchical method called dendogram which displays the mergers that have been made at successive levels. The inputs to a single linkage procedure are the distances between pairs of variables. Clusters are figured from the individual entities by combining the smallest distance. Suppose, the smallest distance in $\mathbf{D}=\left\{d_{i j}\right\}$ and combine the corresponding variables, note, $U$ and $V$, to get cluster $(U V)$. Group $U$ and $V$ are then merged. The distance between $(U V)$ and any other group $W$ are defined as Equation 2.

$$
d_{(U V) W}=\min \left\{d_{U W}, d_{V W}\right\}
$$

where $d_{U W}$ and $d_{V W}$ are the distances between the smallest distance of groups $U$ and $W$, and groups $V$ and $W$, respectively.

\section{RESULTS}

The study results consequently displayed as following.

1. To study the physical patterns of concentration for each of VOCs, the descriptive statistics with mean and standard error was shown and compared to the annual standard in Table 1. Based on the annual standard for each of VOCs concentration (Announcement of the National Environment Board (No. 30) 2007, 2007), it indicated that there were 3 organic compounds valued mean concentration larger than the annual standard. The Mean \pm SE. of benzene, 1,2-dichloroethane and 1,3-butadiene were $2.74 \pm 0.14,1.15 \pm 0.35$ and $0.40 \pm 0.05$, respectively. 
Citation: Jatupat Mekparyup and Kidakan Saithanu., Measurement and Identification Source Characteristic of VOCs in Map Ta Phut Industrial Estate of Thailand using Multivariate Analysis Technique. Australian Journal of Basic and Applied Sciences, 13(8): 64-68. DOI: 10.22587/ajbas.2019.13.8.10

Table 1. The mean, standard error and annual standard for each of VOCs concentration in Map Ta Phut Industrial Estate

\begin{tabular}{|c|c|c|}
\hline VOCs & Mean \pm SE. & Annual Standard $\left(\mu \mathrm{g} / \mathrm{m}^{3}\right)$ \\
\hline 1. Benzene & $\mathbf{2 . 7 4 \pm 0 . 1 4}$ & $\mathbf{1 . 7}$ \\
\hline 2. Vinyl Chloride & $2.08 \pm 1.61$ & 10 \\
\hline 3. 1,2-Dichloroethane & $\mathbf{1 . 1 5} \pm \mathbf{0 . 3 5}$ & $\mathbf{0 . 4}$ \\
\hline 4. Trichloroethylene & $0.20 \pm 0.02$ & 23 \\
\hline 5. Dichloromethane & $1.63 \pm 0.51$ & 22 \\
\hline 6. 1,2-Dichloropropane & $0.11 \pm 0.01$ & 200 \\
\hline 7. Tetrachloroethylene & $0.17 \pm 0.01$ & 0.43 \\
\hline 8. Chloroform & $0.21 \pm 0.04$ & $\mathbf{0 . 3 3}$ \\
\hline
\end{tabular}

2. Principal component extraction of factor analysis was utilized to discover the significant variables resulted in discharging VOCs emission. An appropriate number of principal components is setting equal to the number of eigenvalues which are greater than 1 or nearly to 1 (Kaiser, 1958) also the variation percentage of cumulative proportion is greater than $70 \%$ (Velicer and Jackson, 1990). As of eigenvalue analysis shown in Table 2 as well the scree plot in Figure 1, 5 principal components (PC1-PC5) would be extracted in terms of 5 factors (FA1 to FA5).

Table 2. Eigenvalue, proportion of variation and cumulative proportion of variation for each PC

\begin{tabular}{|l|c|c|c|}
\hline PC & Eigenvalue & Proportion of variation & Cumulative proportion of variation \\
\hline PC1 & 1.9299 & 0.2144 & 0.2144 \\
\hline PC2 & 1.4011 & 0.1557 & 0.3701 \\
\hline PC3 & 1.2626 & 0.1403 & 0.5104 \\
\hline PC4 & 1.0359 & 0.1151 & 0.6255 \\
\hline PC5 & $\mathbf{0 . 8 8 6 5}$ & $\mathbf{0 . 0 9 8 5}$ & $\mathbf{0 . 7 2 4 0}$ \\
\hline PC6 & 0.8646 & 0.0961 & 0.8201 \\
\hline PC7 & 0.6808 & 0.0756 & 0.8957 \\
\hline PC8 & 0.5659 & 0.0629 & 0.9586 \\
\hline PC9 & 0.3728 & 0.0414 & 1.0000 \\
\hline
\end{tabular}

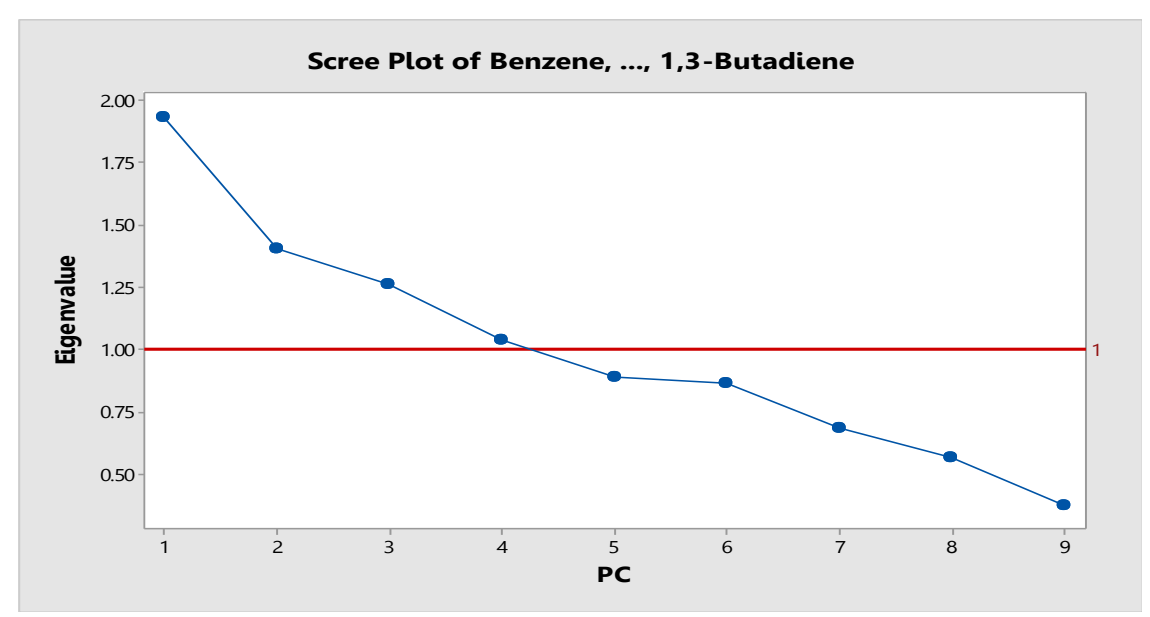

Figure 1. Scree plot of each PC

Since sometime the original loadings of factors may not be easily interpretable, it is usually to rotate them in practice until a simpler structure is obtained. Varimax, one of rotation methods, was then applied. The varimax rotated factor loadings were estimated in Table 3.

Table 3. Estimated varimax rotated loadings of 5 factors

\begin{tabular}{|c|c|c|c|c|c|}
\hline Variable & FA1 & FA2 & FA3 & FA4 & FA5 \\
\hline 1. Benzene & 0.009 & $\mathbf{0 . 7 9 9}$ & -0.246 & 0.208 & 0.019 \\
\hline 2. Vinyl Chloride & -0.045 & $\mathbf{0 . 8 0 8}$ & 0.229 & -0.208 & -0.044 \\
\hline 3. 1,2-Dichloroethane & -0.089 & -0.065 & $\mathbf{- 0 . 7 5 8}$ & -0.053 & 0.066 \\
\hline 4. Trichloroethylene & -0.056 & -0.014 & 0.063 & 0.011 & $\mathbf{0 . 9 8 5}$ \\
\hline 5. Dichloromethane & 0.016 & -0.034 & 0.224 & $\mathbf{0 . 8 5 6}$ & 0.027 \\
\hline
\end{tabular}


Citation: Jatupat Mekparyup and Kidakan Saithanu., Measurement and Identification Source Characteristic of VOCs in Map Ta Phut Industrial Estate of Thailand using Multivariate Analysis Technique. Australian Journal of Basic and Applied Sciences, 13(8): 64-68. DOI: 10.22587/ajbas.2019.13.8.10

\begin{tabular}{|c|c|c|c|c|c|}
\hline 6. 1,2-Dichloropropane & 0.560 & -0.116 & 0.315 & -0.501 & 0.058 \\
\hline 7. Tetrachloroethylene & $\mathbf{0 . 8 1 9}$ & 0.093 & -0.043 & 0.159 & -0.078 \\
\hline 8. Chloroform & $\mathbf{0 . 8 6 3}$ & -0.094 & 0.063 & -0.140 & -0.012 \\
\hline 9. 1,3-Butadiene & 0.019 & 0.086 & $\mathbf{- 0 . 7 6 3}$ & -0.083 & -0.159 \\
\hline \% Variance & 19.37 & 14.84 & 14.45 & 12.50 & 11.24 \\
\hline
\end{tabular}

Liu et al. (2003) classified factor loadings in absolute value of greater than 0.75 as strong, 0.50-0.75 as moderate and 0.3-0.5 as weak. Basing on strong value, it clearly stated as follows.

Factor 1 (FA1) expressed as tetrachloroethylene and chloroform with $19.37 \%$ of total variance.

Factor 2 (FA2) expressed as benzene and vinyl chloride with $14.84 \%$ of total variance.

Factor 3 (FA3) expressed as 1,2-dichloroethane and 1,3-butadiene with $14.45 \%$ of total variance.

Factor 4 (FA4) expressed as dichloromethane with $12.50 \%$ of total variance.

Factor 5 (FA5) expressed as trichloroethylene with $11.24 \%$ of total variance.

That meant, it also presented all these 5 factors could explain $72.4 \%$ of total variance.

3. The amalgation steps of hierarchical technique for combining monitoring stations with similar characteristics and distance level were displayed in Table 4. Dendogram in Figure 2 was also a representative for grouping monitoring stations by the concentrations of VOCs.

Table 4. Cluster analysis of monitoring stations

\begin{tabular}{|c|c|c|c|c|c|c|c|}
\hline Step & $\begin{array}{l}\text { Number of } \\
\text { clusters }\end{array}$ & $\begin{array}{l}\text { Similarity } \\
\text { level }\end{array}$ & $\begin{array}{c}\text { Distance } \\
\text { level }\end{array}$ & \multicolumn{2}{|c|}{$\begin{array}{l}\text { Clusters } \\
\text { jointed }\end{array}$} & $\begin{array}{l}\text { New } \\
\text { cluster }\end{array}$ & $\begin{array}{l}\text { Number of obs. } \\
\text { in new cluster }\end{array}$ \\
\hline 1 & 6 & 95.7200 & 0.085599 & 3 & 6 & 3 & 2 \\
\hline 2 & 5 & 95.1190 & 0.097620 & 2 & 3 & 2 & 3 \\
\hline 3 & 4 & 94.5394 & 0.109213 & 1 & 2 & 1 & 4 \\
\hline 4 & 3 & 88.0229 & 0.239542 & 1 & 4 & 1 & 5 \\
\hline 5 & 2 & 65.5751 & 0.688498 & 1 & 7 & 1 & 6 \\
\hline 6 & 1 & 65.3252 & 0.693495 & 1 & 5 & 1 & 7 \\
\hline
\end{tabular}

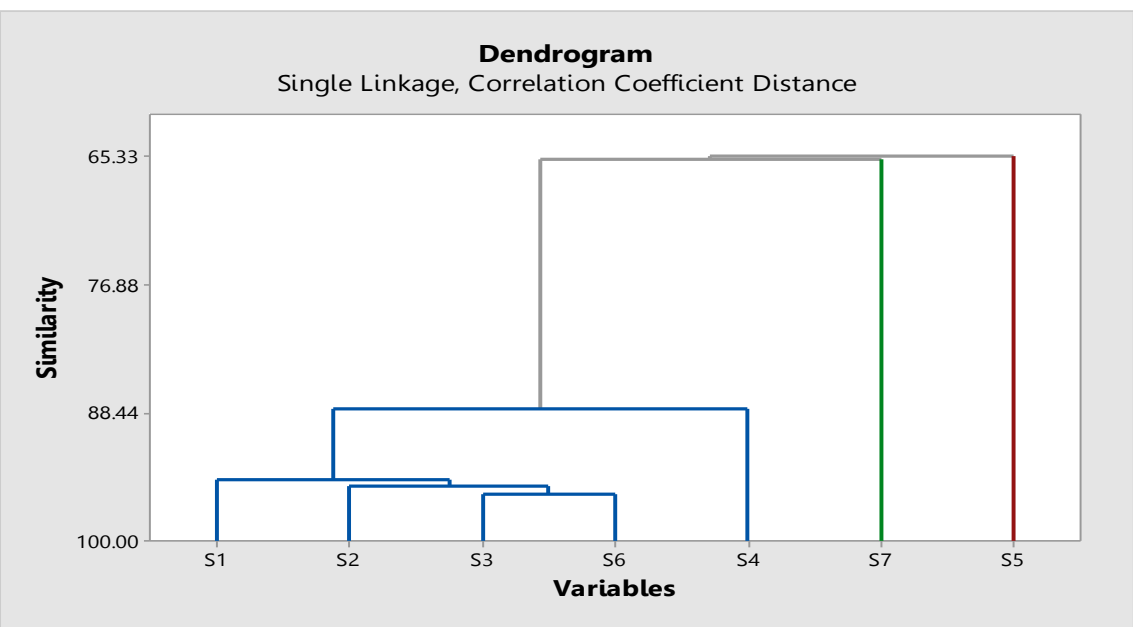

Figure 2. Dendogram for clustering of monitoring stations

As of Table 4 and Figure 2, it distinctly explained that there were 3 clusters for physical patterns of monitoring stations in Map Ta Phut Industrial Estate.

Cluster 1contained 5 monitoring stations; Health Promotion Hospital Map Ta Phut (S1), Map Chalute Temple (S2), Wat Nong Fap School (S3), Muang Mai Map Ta Phut (S4) and Ban Ta Kuan Public Health Center (S6) with rather small concentrations of VOCs.

Cluster 2 is Nop Pakate Village (S7) station with medium concentrations of VOCs.

Cluster 3 is Ban Plong (S5) Community station with the concentrations of VOCs.

\section{DISCUSSION AND CONCLUSION}

Measurement of VOCs concentrations at 7 monitoring stations of Map Ta Phut Industrial Estate during 2007 to 2015 were analyzed by multivariate analysis technique to clearly expose their emission characteristics and source apportionment. Factor loadings of varimax rotation which were greater than 0.75 was only considered for this study. Principal component extraction identified 5 factors substantially affecting the VOCs emission also these factors capably explained $72.4 \%$ of total variance. That implied 3 major source categories influencing on the measured VOC concentrations were respectively emitted from industrial 
process dominated with 1,2-dichloroethane, 1,3-butadiene, dichloromethane and trichloroethylene (FA3-FA5: 38.19\%), activity in household contributed to tetrachloroethylene and chloroform (FA1: 19.37\%), and mobile and non-mobile exhaust accounted for benzene and vinyl chloride (FA2: 14.84\%). This gave the same results of Pollution Control Department report notified the yearly average of 4 concentrations; benzene, 1,3-butadiene, 1,2-dichloroethane and vinyl chloride, were larger than the standard (Air Quality and Noise Management Bureau, Pollution Control Department, 2014). Therefore, the one who authorized should find the way to control and protect air pollution problem resulted from these four VOCs concentrations. To determine physical patterns of monitoring stations, cluster analysis with hierarchical technique and single linkage distinctly classified 3 groups corresponding to the amount of VOC concentration. Cluster 1 was rather small concentrations of VOCs in 5 monitoring stations; Health Promotion Hospital Map Ta Phut (S1), Map Chalute Temple (S2), Wat Nong Fap School (S3), Muang Mai Map Ta Phut (S4) and Ban Ta Kuan Public Health Center (S6). Cluster 2 was medium concentrations of VOCs in Nop Pakate Village (S7). Cluster 3 was large concentrations of VOCs in Ban Plong (S5) Community. Future studies may be able to apply the daily warning average rather than the yearly average of VOC concentrations by use of multivariate technique analysis in identifying and quantifying the source contribution of VOCs for other urban or industrial areas.

\section{ACKNOWLEDGEMENT}

This work was financially supported by the Research Grant of Burapha University through National Research Council of Thailand (Grant no. 77/2560). The authors also thank Air Quality and Noise Management Bureau, Pollution Control Department of Thailand for furnishing all data.

\section{REFERENCES}

Air Quality and Noise Management Bureau, Pollution Control Department. (2014). Quality of air monthly reports. Retrieved June 1, 2014. http://aqnis.pcd.go.th/data/monthly

Announcement of the National Environment Board (No. 30) 2007, (2007, 28 September). Royal Thai Government Gazette. 124(143), 8-9.

GENG, F., CAI, C., TIE, X., YU, Q., AA, J., PENG, L., ZHOU, G., XU, J., 2009. Analysis of VOCs emissions using PCA/APCS receptor model at city of Shanghai, China. J. Atmos Chem 62: 229-247.

GUO, H., WANG, T., SIMPSON, I. J., BLAKE, D. R., YU, X. M., KWOK, Y. H., LI, Y. S., 2004. Source contributions to ambient VOCs and CO at a rural site in eastern China. Atmospheric Environment 38: 4551-4560.

HUANG, C. H., CHEN K. S., WANG H. K., 2012. Measurements and PCA/APCS Analyses of Volatile Organic Compounds in Kaohsiung Municipal Sewer Systems, Southern Taiwan. Aerosol and Air Quality Research 12: 1315-1326.

JOHNSON, R. A., WICHERN, D. W., 2007. Applied Multivariate Statistical Analysis. Prentice-Hall Press, New Jersey.

KAISER, H. F., 1958. The varimax criterion for analytic rotation in factor analysis. Psychometrika 23: 187-200.

KHANTEE, W., THEPANONDH, S., 2014. Source Apportionment Analysis of Airborne Volatile Organic Compounds in Maptaphut, Thailand. International Journal of Environment Science and Development 5: 191-196.

MARCIANO, S., SARITHA, K., KURUVILLA, J., 2008. Source Characterization of Volatile Organic Compounds Affecting the Air Quality in a Coastal Urban Area of South Texas. Int. J. Environ. Res. Public Health 5: 130-138.

THURSTON, G., SPENGLER, J., 1985. A quantitative assessment of source contributions to inhalable particulate matter pollutions in metropolitan Boston. Atmospheric Environment 19: 9-25.

VELICER, W. F., JACKSON, D. N., 1990. Component analysis versus common factor analysis: Someissues in selecting an appropriate procedure. Multivariate behavioral research 25: 1-28. 